\title{
Apolipoprotein A1 to Apolipoprotein B Ratio Measurement
}

National Cancer Institute

\section{Source}

National Cancer Institute. Apolipoprotein A1 to Apolipoprotein B Ratio Measurement. NCI

Thesaurus. Code C147292.

The determination of the ratio of apolipoprotein A1 compared to apolipoprotein B present in a sample. The measurement may be expressed as a ratio or percentage. 